\title{
Presencia de agentes potenciales causantes de infecciones subcutáneas humanas en suelo y plantas en el estado de Puebla, México
}

\author{
Presence in soil and plants of potential agents causing human subcutaneous infections \\ in the state of Puebla, Mexico
}

\author{
Alejandra P. Espinosa Texis ${ }^{1}$, Dalia Castillo Hernández ${ }^{2}$, \\ Miriam Díaz Hernández ${ }^{1}$ y Francisca Hernández Hernández ${ }^{3 *}$
}

\footnotetext{
${ }^{1}$ Centro de Investigaciones en Ciencias Microbiológicas, Instituto de Ciencias, Benemérita Universidad Autónoma de Puebla. Ciudad Universitaria. 72570 Puebla, México.

${ }^{2}$ Centro de Investigación en Biotecnología Aplicada, Instituto Politécnico Nacional. Carretera Estatal Santa Inés Tecuexcomac. 90700 Tepetitla de Lardizabal, Tlaxcala, México.

${ }^{3}$ Departamento de Microbiología y Parasitología, Facultad de Medicina, Universidad Nacional Autónoma de México. Ciudad Universitaria, Delegación Coyoacán. 04510 Ciudad de México, CDMX.

‡Autor responsable (frank-hh@comunidad.unam.mx)
}

\section{RESUMEN}

Los hongos y actinomicetos asociados a infecciones en humanos, se encuentran ampliamente distribuidos en la naturaleza. El suelo y las plantas son el hábitat de numerosos hongos y bacterias. Los campesinos son altamente vulnerables a sufrir heridas y pueden contaminarse con estos microorganismos. Con la finalidad de conocer el número de colonias de los agentes causantes de micosis subcutáneas humanas a partir de la naturaleza, se realizó el aislamiento de los microorganismos respectivos a partir de suelo y plantas en 11 municipios del estado de Puebla. De cada municipio se colectaron 50 muestras, cada una consistió de $10 \mathrm{~g}$ de suelo y $10 \mathrm{~g}$ de hojas de la planta más cercana; se prepararon suspensiones respectivas, las cuales fueron inoculadas en agar dextrosa Sabouraud, incubadas a $28{ }^{\circ} \mathrm{C}$, y revisadas periódicamente para identificar los microorganismos de interés con base en su morfología. De 1100 muestras procesadas, se obtuvieron 441 aislados, de los cuales 281 fueron hongos (133 de suelo y 148 de plantas) y 160 actinomicetos (96 de suelo y 64 de plantas). Los hongos aislados fueron identificados por su morfología macroscópica y microscópica. Los actinomicetos fueron identificados por su morfología macroscópica (colonial) y microscópica, y por pruebas bioquímicas. En mayor proporción se aislaron agentes potenciales de cromoblastomicosis (Fonsecaea pedrosoi y Cladophialophora carrionii), seguidos del agente de esporotricosis (Sporothrix schenckii) y de

Cita recomendada:

Espinosa Texis, A. P., D. Castillo Hernández, M. Díaz Hernández y F. Hernández Hernández. 2017. Presencia de agentes potenciales causantes de infecciones subcutáneas humanas en suelo y plantas en el estado de Puebla, México. Terra Latinoamericana 35: 113-122. los agentes de actinomicetoma (Nocardia brasiliensis y $N$. otitidis-caviarum). Del suelo de Cholula y de plantas de Tecali de Herrera, se obtuvieron el mayor número de aislados fúngicos. Del suelo de Chignahuapan y de plantas de Izúcar de Matamoros se obtuvo el mayor número de aislados de actinomicetos. En este estudio se encontraron, tanto en suelo como en plantas de 11 municipios del estado de Puebla, un alto número de colonias de hongos y actinomicetos causantes de infecciones subcutáneas en humanos, y en una proporción similar a la frecuencia con que las patologías respectivas son reportadas en la literatura mexicana.

Palabras clave: Fonsecaea pedrosoi, Sporothrix schenckii, Madurella spp., Nocardia brasiliensis, actinomicetos, micosis subcutáneas.

\section{SUMMARY}

Microscopic fungi and actinomycetes associated with human infections are widely distributed in nature. Soil and plants are the habitat of numerous fungi and bacteria. Farmers are highly vulnerable as they often sustain wounds contaminated by these microorganisms. In order to determine the number of natural colonies of fungi and actinomycetes that cause human subcutaneous infections, the respective microorganisms from soil and plants in 11 municipalities in the State of Puebla were isolated. Fifty samples from each municipality 
were taken, each consisting of $10 \mathrm{~g}$ of soil and $10 \mathrm{~g}$ of leaves of the nearest plant. Suspensions were prepared, inoculated on Sabouraud dextrose agar, incubated at $28{ }^{\circ} \mathrm{C}$, and periodically examined to identify the microorganisms of interest based on their morphological characteristics. Of 1100 samples processed, 441 isolates were obtained, of which 281 were fungi (133 from soil and 148 from plants) and 160 were actinomycetes (96 from soil and 64 from plants). Fungi were identified by their macroscopic and microscopic morphology. Actinomycetes were identified by their macroscopic and microscopic morphology, and by biochemical tests. The main microorganisms isolated were agents of chromoblastomycosis (Fonsecaea pedrosoi and Cladophialophora verrucosa), followed by the agent of sporotrichosis (Sporothrix schenckii) and agents of actinomycetoma (Nocardia brasiliensis and N. otitidiscaviarum). The soil and plants from Cholula and Tecali de Herrera had the highest density of fungal isolates. From the soil and plants in Chignahuapan and Izúcar de Matamoros the highest number of actinomycetes was obtained. In soils from 11 municipalities in the state of Puebla, we found a high diversity of fungi and actinomycetes that cause subcutaneous infections in humans in plants and in proportions similar to the frequency of the respective pathologies reported in the Mexican literature.

Index words: Fonsecaea pedrosoi, Sporothrix schenckii, Madurella spp., Nocardia brasiliensis, actinomycetes, subcutaneous mycosis.

\section{INTRODUCCIÓN}

Los hongos son organismos que se caracterizan por ser cosmopolitas, con una gran capacidad de adaptación a diversas condiciones ambientales, tienen la capacidad de crecer a diferentes temperaturas $\left(6-55^{\circ} \mathrm{C}\right)$ y requieren baja humedad para desarrollarse (Piontelli, 2014). Estos microorganismos tienen afinidad por diferentes sustratos, en particular por los vegetales y sus detritus presentes en el suelo (Abarca, 2000). Los vegetales, así como el suelo pueden ser fuentes infecciosas potenciales para los individuos que, por razones laborales o accidentales, están expuestos a sufrir heridas susceptibles de ser contaminadas con cualquiera de los hongos presentes en el ambiente (López et al., 2012).
La distribución geográfica de las infecciones subcutáneas en seres humanos, en particular las infecciones causadas por hongos llamadas micosis, en el mundo es muy amplia, predominando en los países con clima tropical y subtropical (Rippon, 1988). Las micosis subcutáneas que se presentan con mayor incidencia en México son la esporotricosis, la cromoblastomicosis y el eumicetoma (Padilla-Desgarennes, 1997; Bonifaz, 2001; López-Martínez y Méndez-Tovar, 2007; Vásquez del Mercado et al., 2012; Vargas-Arzola et al., 2012). Otras infecciones micóticas poco frecuentes son la basidiobolomicosis y la conidiobolomicosis (De León-Bojorge et al., 1988; Mayorga-Rodríguez et al., 1996). Las enfermedades mencionadas se adquieren a través de heridas que se contaminan con los agentes causales, afectan la piel y el tejido subcutáneo, son de evolución crónica y generalmente no ponen en riesgo la vida del hospedero pero sí causan discapacidad física progresiva. Estas infecciones se localizan predominantemente en miembros superiores e inferiores, que son partes corporales expuestas tanto a los traumatismos con pérdida de la continuidad de la piel como a la contaminación de las heridas. De no recibir atención médica, en las heridas se puede establecer un agente fúngico o bacteriano y desarrollarse el proceso infeccioso. En el caso de la esporotricosis, se ha reportado también la inhalación de conidios y micelio como otro mecanismo de infección, aunque son pocos los casos reportados con esta modalidad clínica (Aung et al., 2013). La cromoblastomicosis y el eumicetoma generalmente se presentan en hombres, a diferencia de la esporotricosis que tiene una incidencia similar entre hombres y mujeres (Vásquez del Mercado et al., 2012). Estas micosis han sido consideradas ocupacionales por su mayor frecuencia en campesinos, agricultores, floristas, empacadores de loza y horticultores, quienes frecuentemente están expuestos a heridas y están en contacto con las posibles fuentes de infección, rurales o semiurbanas (Rippon, 1988; Choure et al., 2005).

El objetivo de este trabajo fue determinar la presencia y el número de colonias de agentes potenciales causantes de cromoblastomicosis, esporotricosis y eumicetoma en suelo y plantas, de diferentes municipios del estado de Puebla. Se incluyeron también los agentes causantes de actinomicetoma, patología clínicamente similar al eumicetoma, pero mucho más frecuente en nuestro país. Esta información contribuirá a establecer una correlación entre la microbiota (fúngica y actinomicética) ambiental y la frecuencia reportada de estas patologías en México. 


\section{MATERIALES Y MÉTODOS}

Este estudio se realizó en 11 municipios que están distribuidos en los cuatro puntos cardinales del estado de Puebla: Atlixco, Chignahuapan, Cholula, Ciudad Serdán, Izúcar de Matamoros, Tecali de Herrera, Tecamachalco, Tehuacán, Tepexi de Rodríguez, Puebla y Zacatlán (Figura 1). Estos municipios fueron seleccionados para contar con zonas representativas de todo el estado y porque en trabajos previos se ha encontrado una alta incidencia de infecciones subcutáneas (Munguía- Pérez et al., 2007). De cada lugar de estudio se obtuvieron 50 muestras, con una distancia entre una y otra de por lo menos $100 \mathrm{~m}$. Cada muestra consistió de $10 \mathrm{~g}$ de planta (hojas) y $10 \mathrm{~g}$ de suelo (tomados con ayuda de tijeras y cucharillas estériles respectivamente). Las hojas de planta fueron puestas a deshidratar a temperatura ambiente (temperatura diurna: 20 a $29{ }^{\circ} \mathrm{C}$; temperatura nocturna: 12 a $18{ }^{\circ} \mathrm{C}$ ) durante una semana y después maceradas en un mortero estéril, para obtener fragmentos de aproximadamente $5 \mathrm{~mm}$ para colocarlos en respectivos tubos de ensayo; previamente homogenizada la muestra original, se tomó
$1 \mathrm{~g}$ de material vegetal o de suelo, el cual fue mezclado con $9 \mathrm{~mL}$ de agua destilada estéril, para posteriormente hacer diluciones 1:10, 1:100 y 1:1000. De cada una de las diluciones, $500 \mathrm{~mL}$ fueron distribuidos en placas de agar dextrosa Sabouraud (ADS, Bioxon) y Agar Mycosel (BBL; cicloheximida $0.4 \mathrm{~g} \mathrm{~L}^{-1}$, cloranfenicol $0.05 \mathrm{~g} \mathrm{~L}^{-1}$ ). Las muestras fueron incubadas a $28^{\circ} \mathrm{C}$ por un periodo máximo de treinta días. Cada tres días las placas fueron revisadas para detectar el crecimiento de hongos y actinomicetos causantes de infecciones subcutáneas. Los diferentes hongos reportados fueron identificados considerando sus características morfológicas, tanto macro- (de las colonias) como microscópicas, utilizando un microscopio óptico (Labomed), considerando el tipo de conidiogénesis de cada aislado (de Hoog et al., 2000). La identificación de los agentes de cromoblastomicosis se determinó inicialmente por la aparición de colonias pigmentadas (de verde oscuro a negro); después se realizó un examen directo, y en los casos sugestivos de los géneros buscados, se corroboró su morfología y conidiogénesis a través de microcultivos. El agente de esporotricosis, se identificó por la presencia de colonias blancas

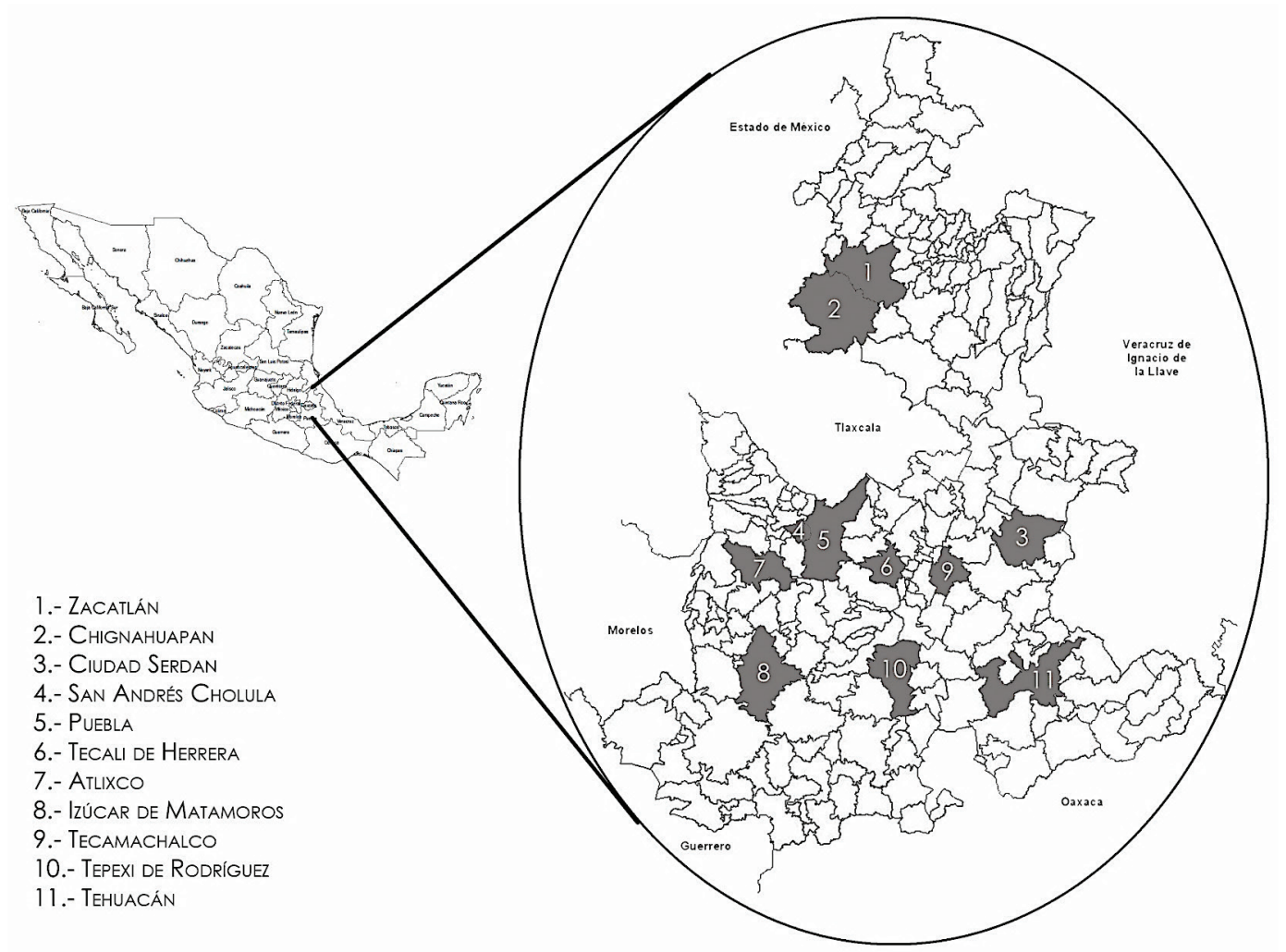

Figura 1. Distribución de los municipios del estado de Puebla de donde se obtuvieron las muestras para el presente estudio. 
o pigmentadas, con aspecto membranoso, húmedo, o velloso en algunos casos; se realizó un examen microscópico, además de microcultivo. En los casos en que el hongo era morfológicamente compatible con Sporothrix, se indujo la reversión a levadura en agar infusión cerebro corazón (BHI, Bioxon), incubado a $37{ }^{\circ} \mathrm{C}$ por cinco días; la reversión a levadura fue puesta en evidencia por examen microscópico. Respecto a la presencia de agentes de eumicetoma, el estudio fue enfocado a los agentes más frecuentes: Madurella spp., Medicopsis (sin. Pyrenochaeta) sp. y Scedosporium sp., por lo que se consideraron las siguientes características de las colonias para su diferenciación: aspecto velloso o algodonoso, de color blanco, gris, marrón claro u oscuro; para determinar el género y la especie de M. mycetomatis, se hizo un subcultivo en agar harina de maíz (Bioxon) para inducir la formación de fiálides. Para la identificación de bacterias causantes de actinomicetoma, se consideró inicialmente el crecimiento lento de las colonias, de aspecto céreo, cuyo color fue variable (blanco, amarillo, naranja, rojo); de las colonias sugestivas, se realizó una tinción de Kinyoun y en caso de tratarse de bacterias filamentosas, se procedió a sub-cultivarlas en agar dextrosa Sabouraud durante cinco a siete días a $28{ }^{\circ} \mathrm{C}$, para después realizar diferentes pruebas bioquímicas (producción de caseinasa, ureasa y almidón, asimilación de xantina, hipoxantina y gelatina) en placas del agar respectivo (agar caseína, agar xantina, agar hipoxantina, agar gelatina) para detectar los patrones de hidrólisis y asimilación de los sustratos de acuerdo a Brown-Elliott et al. (2006). Finalmente se identificaron las plantas en cuyo suelo se encontraron los hongos y bacterias de interés.

\section{RESULTADOS Y DISCUSIÓN}

Se procesó un total de 1100 muestras, de las cuales se obtuvieron 441 aislados: 281 de hongos y 160 de actinomicetos (bacterias). En los Cuadros 1 y 2 se muestra la distribución por municipio de los aislados fúngicos obtenidos de las dos fuentes (suelo y plantas, respectivamente). De las 11 comunidades estudiadas se recuperaron los agentes etiológicos más frecuentemente reportados como causantes de esporotricosis (Sporothrix sp.), micetoma (Madurella spp. y diversos actinomicetos) y cromoblastomicosis (Fonsecaea pedrosoi, Phialophora verrucosa y Cladophialophora carrionii). El número de colonias obtenido a partir de las diferentes diluciones del inóculo no mostró una diferencia definida. La mayoría de los agentes de cromoblastomicosis, eumicetoma y actinomicetoma se obtuvieron de ADS sin antibióticos; S. schenckii fue recuperado con mayor facilidad y frecuencia de ADS con antibióticos.

Cuadro 1. Agentes potenciales causantes de micosis subcutáneas aislados a partir de $\mathbf{5 5 0}$ muestras de suelo de diferentes municipios del estado de Puebla.

\begin{tabular}{|c|c|c|c|c|c|c|c|c|}
\hline Municipio & $\begin{array}{c}\text { Phialophora } \\
\text { verrucosa }\end{array}$ & $\begin{array}{c}\text { Fonsecaea } \\
\text { pedrosoi }^{\dagger}\end{array}$ & $\begin{array}{c}\text { Rhinocladiella } \\
\text { aquaspersa }^{\dagger}\end{array}$ & $\begin{array}{c}\text { Cladophialophora } \\
\text { carrionii }^{\dagger}\end{array}$ & $\begin{array}{l}\text { Sporothrix } \\
\text { schenckii }^{*}\end{array}$ & Madurella sp. ${ }^{\S}$ & $\begin{array}{c}\text { Madurella } \\
\text { mycetomatis }^{\S}\end{array}$ & Total \\
\hline Atlixco & 2 & 2 & 0 & 7 & 6 & 0 & 0 & 17 \\
\hline Cholula & 6 & 10 & 0 & 4 & 1 & 1 & 0 & 22 \\
\hline Ciudad Serdán & 2 & 1 & 0 & 0 & 0 & 0 & 3 & 6 \\
\hline Puebla & 0 & 3 & 0 & 3 & 0 & 0 & 0 & 6 \\
\hline Tecali de Herrera & 0 & 2 & 0 & 2 & 2 & 0 & 0 & 6 \\
\hline Tecamachalco & 4 & 3 & 0 & 2 & 2 & 7 & 0 & 18 \\
\hline Tehuacán & 0 & 3 & 0 & 0 & 3 & 0 & 3 & 9 \\
\hline Tepexi de Rodríguez & 1 & 3 & 0 & 0 & 3 & 0 & 3 & 10 \\
\hline
\end{tabular}

Agentes de: ${ }^{\dagger}$ Cromoblastomicosis; ${ }^{\ddagger}$ Esporotricosis; ${ }^{\S}$ Eumicetoma. Madurella sp.: aislados que formaron colonias y micelio similar a $M$. mycetomatis, pero no formaron esclerotes ni fiálides. ^ Los números indican número de colonias obtenidas. Los números entre paréntesis indican porcentaje. 
Cuadro 2. Agentes potenciales causantes de micosis subcutáneas aislados a partir de 550 muestras de plantas de diferentes municipios del estado de Puebla.

\begin{tabular}{|c|c|c|c|c|c|c|c|c|}
\hline Municipio & $\begin{array}{l}\text { Phialophora } \\
\text { verrucosa }\end{array}$ & $\begin{array}{c}\text { Fonsecaea } \\
\text { pedroso }^{\dagger}\end{array}$ & $\begin{array}{c}\text { Rhinocladiella } \\
\text { aquaspersa }^{\dagger}\end{array}$ & $\begin{array}{c}\text { Cladophialophora } \\
\text { carrionii }^{\dagger}\end{array}$ & $\begin{array}{l}\text { Sporothrix } \\
\text { schenckii }\end{array}$ & Madurella sp. ${ }^{\S}$ & $\begin{array}{c}\text { Madurella } \\
\text { mycetomatis }\end{array}$ & Total \\
\hline Atlixco & 1 & 1 & 0 & 4 & 5 & 0 & 0 & 11 \\
\hline Chigna-huapan & 0 & 11 & 0 & 5 & 0 & 0 & 0 & 16 \\
\hline Cholula & 4 & 7 & 0 & 1 & 0 & 1 & 0 & 13 \\
\hline Ciudad Serdán & 0 & 2 & 0 & 1 & 0 & 0 & 2 & 5 \\
\hline Izúcar de Matamoros & 0 & 2 & 1 & 1 & 4 & 0 & 1 & 9 \\
\hline Puebla & 0 & 3 & 0 & 6 & 1 & 0 & 0 & 10 \\
\hline Tecali de Herrera & 8 & 10 & 0 & 15 & 4 & 0 & 0 & 37 \\
\hline Tecama-chalco & 3 & 3 & 0 & 2 & 1 & 6 & 0 & 15 \\
\hline Tehuacán & 0 & 2 & 0 & 1 & 1 & 0 & 2 & 6 \\
\hline Tepexi de Rodríguez & 0 & 1 & 0 & 1 & 3 & 0 & 2 & 7 \\
\hline Zacatlán & 0 & 10 & 0 & 9 & 0 & 0 & 0 & 19 \\
\hline \multirow[t]{2}{*}{ Total" } & 16 & 52 & 1 & 46 & 19 & 7 & 7 & 148 \\
\hline & (10.8) & $(35.2)$ & $(0.7)$ & (31.1) & (12.8) & $(4.7)$ & $(4.7)$ & (100) \\
\hline
\end{tabular}

Agente de: ${ }^{\dagger}$ Cromoblastomicosis; ${ }^{\ddagger}$ Esporotricosis; ${ }^{\S}$ Eumicetoma. Madurella sp.: aislados que formaron colonias y micelio similares a M. mycetomatis, pero no formaron esclerotes ni fiálides. " Los números indican número de colonias obtenidas. Los números entre paréntesis indican porcentaje.

De los 281 hongos aislados, 133 (47.3\%) fueron recuperados de suelo, y 148 (52.7\%) de plantas. En ambas fuentes, el número de colonias más alto correspondió a los hongos Fonsecaea pedrosoi y Cladophialophora carrionii como agentes de cromoblastomicosis, seguidos de Sporothrix schenckii, principal agente causal de la esporotricosis en México; los agentes causales de eumicetoma fueron los hongos menos abundantes. Solamente se obtuvo un aislado de suelo y uno de planta de Rhinocladiella aquaspersa, agente de cromoblastomicosis.

Se muestran imágenes representativas de los aislados fúngicos obtenidos en este trabajo en la Figura 2. Las colonias (Figura 2A-C) y los microcultivos (Figura 2D-F) están crecidos en ADS sin antibiótico; el microcultivo de la Figura 2G, en agar papa dextrosa; fiálides de $M$. mycetomatis $(2 \mathrm{H})$ inducidas en agar harina de maíz.

Geográficamente, los aislados fúngicos fueron más numerosos en el suelo de Cholula e Izúcar de Matamoros, y en las plantas Agave sp. (maguey), Yucca filifera (yuca), Jacaranda mimosaefalia (jacaranda), Eucalyptus camaldulensis (eucalipto), Oreodoxa regia (palma), Cupressus lindleyi (pino), Mamilaria elegans (cactácea), Opuntia sp. (nopal) y Schinus molle (pirúl), de Tecali de Herrera y Zacatlán. De los municipios de Chignahuapan y Ciudad Serdán se recuperó el menor número de aislados fúngicos de suelo y de plantas respectivamente. En los diferentes municipios de donde se obtuvieron las muestras, existen diferentes condiciones climáticas y diferentes tipos de suelo. Es probable que estas diferencias determinen el tipo y número de poblaciones fúngicas y actinomicetos, como se observó en este estudio.

Los 160 agentes de actinomicetoma aislados, de los cuales 96 fueron recuperados de suelo y 64 de plantas se muestran en los Cuadros 3 y 4 . De los 96 aislados de suelo (Cuadro 3), 78 (81.2\%) correspondieron al género Nocardia, predominando N. brasiliensis $(44.8 \%$ del total de aislados). Actinomadura madurae representó el $10.4 \%$ de los aislados recuperados de suelo.

De los actinomicetos aislados de plantas (Cuadro 4), la tendencia de la presencia de Nocardia fue similar al de suelo (84.4\% en total); sin embargo, el segundo lugar fue ocupado por A. pelletieri (9.3\%), seguido de A. madurae y $S$. somaliensis (3.1\% para cada uno).

El mayor número de aislados bacterianos fue obtenido del suelo de Chignahuapan, Tecamachalco y Tehuacán, y de las plantas de Izúcar de Matamoros, Tecamachalco y Tehuacán.

Las plantas relacionadas con los aislamientos de agentes de cromoblastomicosis fueron: Agave sp. (maguey), Yucca filifera (yuca), Jacaranda mimosaefalia (jacaranda), Eucalyptus 


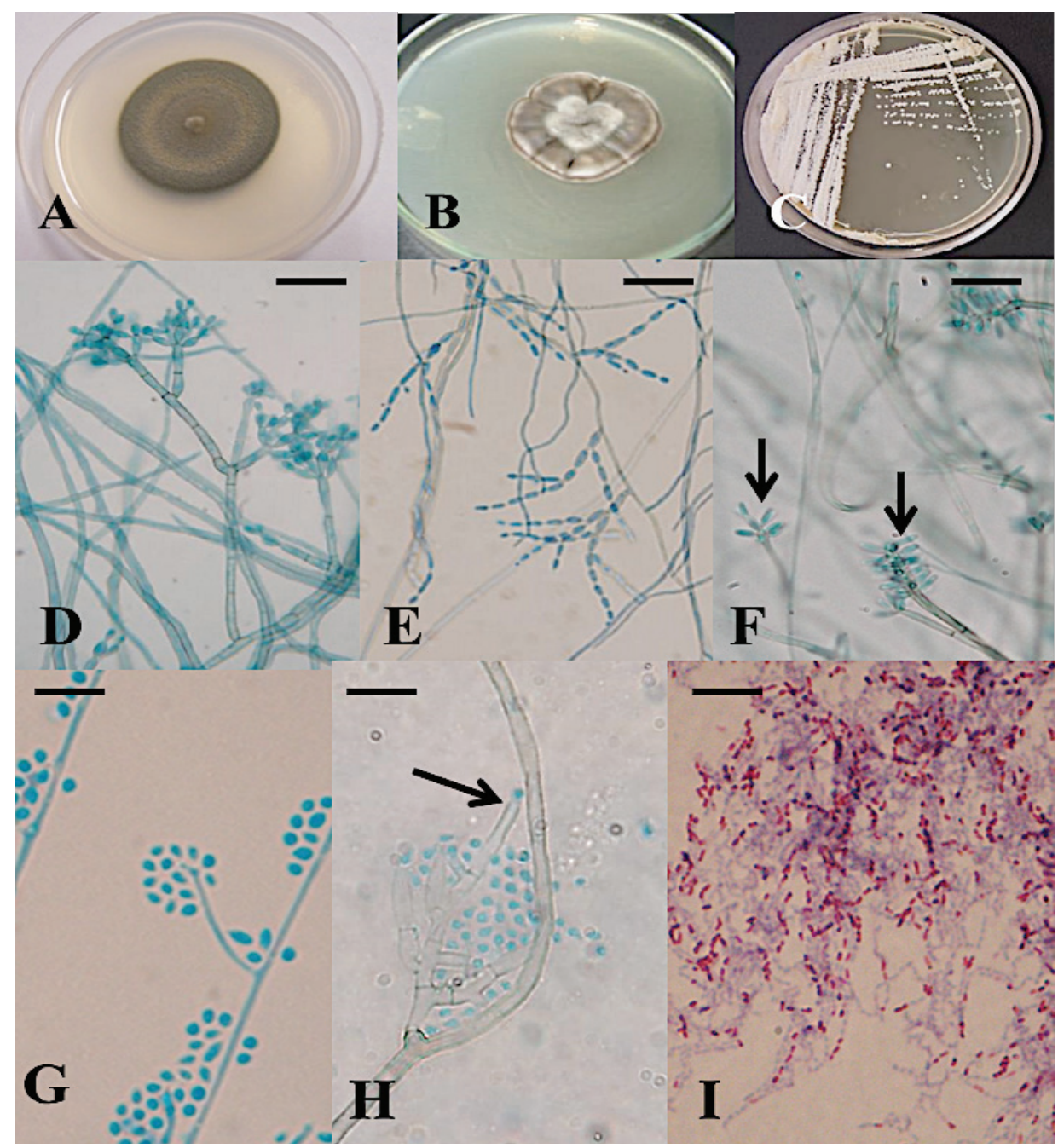

Figura 2. Morfología de aislados obtenidos de plantas y suelos del estado de Puebla. Colonias de Cladophialophora carrionii (A: pigmentada, vellosa), Sporothris schenckii (B: variedad pigmentada, membranosa) y Nocardia brasiliensis (C: aspecto céreo, color naranja). Examen microscópico contrastado con azul de lactofenol de Fonsecaea pedrosoi (D: conidióforos ramificados, con cadenas cortas de conidios), C. carrionii (E: cadenas largas de conidios), Rhinocladiela aquaspersa (F: conidios alargados (flechas) formados en el extremo de conidióforos simples), S. schenckii (G: conidióforos largos en cuyo extremo se forman simpoduloconidios ovoides) y Madurella mycetomatis (H: fiálides casi transparentes (flecha) de donde surgen pequeños conidios). Frotis de $N$. brasiliensis teñido con Kinyoun (I: filamentos bacterianos, con estructuras cocoides y bacilares). (Imágenes D a I: tomadas a 100X). Barra de escala: $20 \mu \mathrm{m}$.

camaldulensis (eucalipto), Dahlia coccinea (dalia silvestre), Prosopis sp. (rompebotitas), Zea mays (maíz), Rosa centifolia (rosa), Castilleja tenuiflora (mirto), Oreodoxa regia (palma), Cupressus lindleyi (pino), Mamilaria elegans (cactácea), Opuntia sp. (nopal).

Las plantas relacionadas con los aislamientos de agentes de micetoma principalmente fueron: Jacaranda mimosaefalia, Prosopis sp., Pithecellobium sp. (guamuchil), Saccharum officinarum (caña de azúcar), Festiuca tolusensis (pastizal), Baccharis conferta (escobilla), Simsia amplexicaulis (acahual suave), Zea mays, Agave sp., Rosa centifolia, Schinus molle (pirúl) Opuntia sp.

Las plantas relacionadas con los aislamientos de agentes de esporotricosis fueron: Eucalyptus camaldulensis, Rosa centifolia, Zea mays, Curcurbita sp., Stenocereus marginatus (órgano), Cupressus lindleyi, Jacaranda mimosaefalia, Oreodoxa regia (palma). 
Cuadro 3. Agentes potenciales causantes de actinomicetoma aislados a partir de suelo de diferentes municipios del estado de Puebla.

\begin{tabular}{|c|c|c|c|c|c|c|c|}
\hline Municipio & $\begin{array}{c}\text { Nocardia } \\
\text { otitidis- } \\
\text { caviarum }\end{array}$ & $\begin{array}{c}\text { Nocardia } \\
\text { brasiliensis }\end{array}$ & $\begin{array}{l}\text { Nocardia } \\
\text { asteroides }\end{array}$ & $\begin{array}{c}\text { Actinomadura } \\
\text { pelletieri }\end{array}$ & $\begin{array}{c}\text { Actinomadura } \\
\text { madurae }\end{array}$ & $\begin{array}{c}\text { Streptomyces } \\
\text { somaliensis }\end{array}$ & Total \\
\hline Atlixco & 1 & 0 & 0 & 1 & 0 & 0 & 2 \\
\hline Chignahuapan & 5 & 14 & 1 & 0 & 5 & 0 & 25 \\
\hline Cholula & 2 & 0 & 0 & 1 & 0 & 0 & 3 \\
\hline Ciudad Serdán & 0 & 1 & 0 & 0 & 1 & 0 & 2 \\
\hline Izúcar de Matamoros & 0 & 8 & 3 & 0 & 1 & 1 & 13 \\
\hline Puebla & 0 & 2 & 0 & 0 & 0 & 0 & 2 \\
\hline Tecali de Herrera & 2 & 6 & 0 & 3 & 0 & 0 & 11 \\
\hline Tecamachalco & 14 & 0 & 0 & 1 & 0 & 0 & 15 \\
\hline Tehuacán & 0 & 7 & 5 & 0 & 2 & 1 & 15 \\
\hline Tepexi de Rodríguez & 0 & 3 & 2 & 0 & 1 & 0 & 6 \\
\hline Zacatlán & 0 & 2 & 0 & 0 & 0 & 0 & 2 \\
\hline Total ${ }^{\pi}$ & $\begin{array}{c}24 \\
(25)\end{array}$ & $\begin{array}{c}43 \\
(44.8)\end{array}$ & $\begin{array}{c}11 \\
(11.5)\end{array}$ & $\begin{array}{c}6 \\
(6.2)\end{array}$ & $\begin{array}{c}10 \\
(10.5)\end{array}$ & $\begin{array}{c}2 \\
(2)\end{array}$ & $\begin{array}{c}96 \\
(100)\end{array}$ \\
\hline
\end{tabular}

ॠ Los números indican número de colonias obtenidas. Los números entre paréntesis indican porcentaje.

Los tipos de suelo relacionados con los agentes de micetoma y esporotricosis fueron regosol y vertisol y para los agentes de cromoblastomicosis fueron regosol y feozem. El regosol es un tipo de suelo poco desarrollado y se forma a partir de material no consolidado y en lugares con pendientes acusadas; su capacidad agrícola es baja. El vertisol es un suelo mineral condicionado por el material sobre el que se ha formado; es de color oscuro y contiene abundante arcilla, material que al secarse suele formar grietas verticales, anchas y profundas. El feozem es un tipo de suelo rojizo de las regiones conocidas como praderas o pastizales, con alta saturación de bases y rico en nutrientes; los feozem no perturbados son muy fértiles. Los suelos de los cuales se obtuvieron los aislados de este estudio tuvieron un $\mathrm{pH}$ que osciló entre 6.5 y 7.3.

Cuadro 4. Agentes potenciales causantes de actinomicetoma aislados a partir de plantas de diferentes municipios en el estado de Puebla.

\begin{tabular}{|c|c|c|c|c|c|c|c|}
\hline Municipio & $\begin{array}{l}\text { Nocardia } \\
\text { otitidis- } \\
\text { caviarum }\end{array}$ & $\begin{array}{c}\text { Nocardia } \\
\text { brasiliensis }\end{array}$ & $\begin{array}{l}\text { Nocardia } \\
\text { asteroides }\end{array}$ & $\begin{array}{c}\text { Actinomadura } \\
\text { pelletieri }\end{array}$ & $\begin{array}{c}\text { Actinomadura } \\
\text { madurae }\end{array}$ & $\begin{array}{c}\text { Streptomyces } \\
\text { somaliensis }\end{array}$ & Total \\
\hline Atlixco & 1 & 0 & 0 & 0 & 0 & 0 & 1 \\
\hline Chignahuapan & 0 & 1 & 0 & 0 & 0 & 0 & 1 \\
\hline Cholula & 2 & 0 & 0 & 0 & 0 & 0 & 2 \\
\hline Ciudad Serdán & 0 & 1 & 0 & 0 & 0 & 0 & 1 \\
\hline Izúcar de Matamoros & 0 & 18 & 1 & 0 & 1 & 1 & 21 \\
\hline Puebla & 0 & 3 & 0 & 0 & 0 & 0 & 3 \\
\hline Tecali de Herrera & 0 & 3 & 0 & 3 & 1 & 0 & 7 \\
\hline Tecamachalco & 7 & 0 & 0 & 3 & 0 & 0 & 10 \\
\hline Tehuacán & 0 & 5 & 3 & 0 & 0 & 1 & 9 \\
\hline Tepexi de Rodríguez & 0 & 2 & 2 & 0 & 0 & 0 & 4 \\
\hline Zacatlán & 0 & 2 & 3 & 0 & 0 & 0 & 5 \\
\hline Total ${ }^{\pi}$ & $\begin{array}{c}10 \\
(15.7)\end{array}$ & $\begin{array}{c}35 \\
(54.7)\end{array}$ & $\begin{array}{c}9 \\
(14)\end{array}$ & $\begin{array}{c}6 \\
(9.4)\end{array}$ & $\begin{array}{c}2 \\
(3.1)\end{array}$ & $\begin{array}{c}2 \\
(3.1)\end{array}$ & $\begin{array}{c}64 \\
(100)\end{array}$ \\
\hline
\end{tabular}

'Los números indican número de colonias. Los números entre paréntesis indican porcentaje. 
México, por sus condiciones climáticas heterogéneas, es ideal para el desarrollo de una gran diversidad de hongos y bacterias en fuentes naturales. Por su capacidad de crecimiento óptimo a diferentes temperaturas, los hongos se han clasificado en psicrófilos $\left(0-20^{\circ} \mathrm{C}\right)$, mesófilos $\left(0-50^{\circ} \mathrm{C}\right)$ y termófilos (20-50 ${ }^{\circ} \mathrm{C}$, pero están mejor adaptados a aguas termales y zonas desérticas (Méndez-Tovar, 2012). De acuerdo a datos del INEGI2006, en el estado de Puebla predominan los climas templados con diversos grados de humedad, con temperaturas que oscilan entre 0 y $29{ }^{\circ} \mathrm{C}$, y una pluviosidad entre 400 y $4000 \mathrm{~mm}$. Algunos ejemplos de la diversidad climática en los municipios incluidos en este estudio son: templado húmedo: Zacatlán; cálido sub-húmedo: Izúcar de Matamoros; semi-cálido subhúmedo: Tepexi de Todríguez, Cholula, Atlizco, Tecali de Herrera; Templado: Puebla; templado sub-húmedo: Tecamachalco; seco, muy cálido y caliente: Tehuacán. Estas condiciones son altamente favorables para el crecimiento de hongos y bacterias. La abundancia de estos microorganismos en el suelo y plantas con que los humanos interactúan durante sus actividades laborales, podrían explicar parcialmente la frecuencia con que los individuos son infectados por ellos. Así, en este estudio entre los agentes causales de cromoblastomicosis se aisló a $F$. pedrosoi; como único agente de esporotricosis se aisló a $S$. schenckii (aunque existen otras especies, en México éste es el principal agente identificado (Madrid et al., 2009); como principal agente de eumicetoma se encontró a Madurella spp.; y como principal agente de actinomicetoma se aisló a $N$. brasiliensis. La literatura sustenta a estos agentes como las principales causas de la infección respectiva y demostrada por su aislamiento e identificación a partir de los tejidos infectados. En algunos estudios documentan el antecedente de haber sufrido una herida y la aparición de lesiones compatibles con una micosis subcutánea (Dixon et al., 1991; Aguilar et al., 2011).

En un reporte del Centro Dermatológico "Ladislao de la Pascua", se informa que las micosis subcutáneas atendidas con mayor frecuencia y diagnosticadas en el Laboratorio de Micología fueron la esporotricosis y la cromoblastomicosis (Padilla-Desgarennes et al., 1997). A pesar de que este estudio no es reciente, es representativo del número de casos que actualmente prevalece. Estudios complementarios a éste han sido publicados en años más recientes (Bonifaz et al., 2001; López Martínez y Méndez-Tovar, 2007; Madrid et al.,
2009; Vásquez del Mercado et al., 2012; RomeroNavarrete et al., 2014). En un estudio sobre micetomas en México se observó que, de todos los casos conocidos, el actinomicetoma se presenta con una frecuencia de $96.52 \%(65.58 \%$ son causados por $N$. brasiliensis) y el eumicetoma representa el 3.48\% del total (LópezMartínez et al., 2013).

El número total de aislados recuperados en este trabajo es equivalente a la frecuencia con que estos microorganismos han sido reportados como agentes causantes de infecciones subcutáneas en algunos centros micológicos mexicanos. En primer lugar se encuentran los agentes de cromoblastomicosis seguidos de los agentes de actinomicetoma, esporotricosis y eumicetoma. El agente más frecuente de cromoblastomicosis, tanto aislado de la naturaleza en el presente estudio, como reportado a partir de casos clínicos, es F. pedrosoi (Bonifaz et al., 2001; Lugo-Ayala et al., 2002; Romero Navarrete et al., 2014). Rhinocladiella aquaspersa, otro agente de cromoblastomicosis, fue aislado solo en dos ocasiones (una de suelo y otra de planta) y pocas veces han sido reportados como agentes de infección en México (Badali et al., 2010; González et al., 2013). Esta misma tendencia se observó en el caso del actinomicetoma cuyo principal agente es $N$. brasiliensis, actinomiceto que también fue aislado predominantemente de fuentes naturales en este estudio. Es altamente probable que la incidencia de los casos de cromoblastomicosis y actinomicetoma esté dada por la virulencia de los agentes causales: hay abundancia de hongos pigmentados en la naturaleza, pero generalmente son de baja virulencia, y esto explicaría su menor frecuencia como causa de infección entre las tres micosis subcutáneas. De los actinomicetos, $N$. brasiliensis es el agente más frecuente de actinomicetoma y probablemente esto se deba a que este microorganismo es el más virulento de su grupo, pero también el más abundante en la naturaleza. Respecto a $S$. schenckii sensu stricto, se sabe que es el agente causal de la micosis subcutánea más frecuente en México, y este evento estaría determinado por la virulencia atribuida a este hongo (Barros et al., 2011). Puebla es un estado que ha atraído la atención de diferentes investigadores por las condiciones climáticas, laborales y culturales que favorecen la presencia de diferentes micosis, particularmente la esporotricosis (Espinosa-Texis et al., 2001; MacotelaRuiz y Nochebuena-Ramos, 2006), cuyo agente causal 
ha sido demostrado en fuentes naturales (MunguíaPérez, et al., 2007). La presencia de los actinomicetos en suelo mexicano ha sido previamente reportada en el estado de Morelos. En ese estudio se detectó a $N$. brasiliensis como actinomiceto predominante (20.8\%), seguido de $N$. asteroides (8.3\%), $N$. otitidis-caviarum (6.2\%), A. madurae (2.8\%), S. somaliensis $(1.1 \%)$ y A. pelletieri (0.8\%) (Castañón-Olivares et al., 1992). Estudios en otras partes del mundo han sido enfocados al aislamiento de actinomicetos de importancia médica (Reza, 2009; Kachuei, 2012).

\section{CONCLUSIONES}

- Se logró determinar la frecuencia de hongos y actinomicetos causantes de infección subcutánea humana, a partir de suelo y plantas de 11 municipios del estado de Puebla. Los autores consideramos que la abundancia de un microorganismo en el suelo y plantas está parcialmente relacionada con la frecuencia de esta infección en los humanos. Si un agente infeccioso específico es más abundante que otros, es más probable que los pacientes en riesgo desarrollen una infección por ese agente. La abundancia de los principales agentes de micosis subcutáneas en fuentes naturales es equivalente a la frecuencia con que se aíslan esos microorganismos a partir de zonas corporales infectadas en el humano. Los hongos y actinomicetos aislados con mayor frecuencia en este estudio corresponden con los mismos microorganismos identificados a partir de las lesiones humanas de esportoricosis, cromoblastomicosis, actinomicetoma y eumicetoma en estadísticas nacionales.

- La importancia del presente trabajo radica en que probablemente es el primer reporte sobre el aislamiento integral de agentes de micosis subcutáneas a partir de fuentes naturales en México.

\section{AGRADECIMIENTOS}

A la QFB Érika Córdova Martínez por su valiosa colaboración técnica (Departamento de Microbiología y Parasitología, Facultad de Medicina, UNAM). Este trabajo fue financiado por la Benemérita Universidad Autónoma de Puebla, Proyectos VIEP ESTA NAT15, 16 y 17.

\section{LITERATURA CITADA}

Abarca, M. L. 2000. Taxonomía e identificación de especies implicadas en la aspergilosis nosocomial. Rev. Iberoam. Micol. 17: 79-84.

Aguilar D., A., E. Torres, R. Arenas, F. Hernández-Hernández, L. López, S. Criales-Vera, and M. A. Teliz-Meneses. 2011. Mycetoma caused by Phaeoacremonium parasiticum -a case confirmed by B-tubulin sequence analysis. Mycoses 54: e615-e618.

Aung, A. K., B. M. Teh, C. McGrath, and P. J. Thompson. 2013. Pulmonary sporotrichosis: Case series and systematic analysis of literature on clinic-radiological patterns and management outcomes. Med. Mycol. 51: 534-544.

Badali, H., A. Bonifaz, T. Barrón-Tapia, D. Vázquez-González, L. Estrada-Aguilar, N. M. Oliveira, J. F. Sobral-Filho, J. Guarro, J. F. Meis, and G. S. De Hoog. 2010. Rhinocladiella aquaspersa, proven agent of verrucous skin infection and a novel type of chromoblastomycosis. Med. Mycol. 48: 696-703.

Barros, M. B., R. de Almeida-Paes, and A. O. Schubach. 2011. Sporothrix schenckii and sporotrichosis. Clin. Microbiol. Rev. 24: 633-654.

Bonifaz, A., E. Carrasco-Gerard, and A. Saúl. 2001. Chromoblastomycosis: Clinical and mycologic experience of 51 cases. Mycoses 44: 1-7.

Brown-Elliott, B. A., J. M. Brown, P. S. Conville, and R. J. Jr. Wallace. 2006. Clinical and laboratory features of the Nocardia spp. based on current molecular taxonomy. Clin. Microbiol. Rev. 19: 259-282.

Castañón-Olivares, L. R., P. Manzano-Gayosso, F. HernándezHernández, R. Romero-Martínez y R. López-Martínez. 1992. Aislamiento de Actinomicetos patógenos en una zona endémica de micetomas en México. Rev. Mex. Micol. 8: $111-120$

Choure, A. J., R. K. Shrestha, S. P. Larosa, and A. C. Mehta. 2005. Fever, chills, and chest radiographic infiltrates in a middleaged woman. Cleve. Clin. J. Med. 72: 367-369, 373-374.

De Hoog, G. S., G. J. Guarro, and M. J. Figueras. 2000. Atlas of clinical fungi. Centraalbureau voor Schimmel cultures Utrecht, Universitat Rovira i virgili Reus.

De León-Bojorge, B., R. Ruiz-Maldonado, and R. López-Martínez. 1988. Subcutaneous phycomycosis caused by Basidiobolus haptosporus: A clinicopathologic and mycologic study in a child. Pediatr. Dermatol. 5: 33-36.

Dixon, D. M., F. Salkin, R. A. Duncan, N. J. Hurd, J. H. Haines, M. E. Kemna, and F. B. Coles. 1991. Isolation and characterization of Sporothrix schenckii from clinical and environmental sources associated with the largest U.S. epidemic of sporotrichosis. J. Clin. Microbiol. 29: 1106-1113.

Espinosa-Texis, A., F. Hernández-Hernández, P. Lavalle, J. BarbaRubio y R. López-Martínez. 2001. Estudio de 50 pacientes con esporotricosis. Evaluación clínica y de laboratorio. Gac. Méd. Méx. 137: 111-116.

González, G. M., O. C. Rojas, J. G. González, Y. Kang, and G. S. de Hoog. 2013. Chromoblastomycosis caused by Rhinocladiella aquaspersa. Med. Mycol. Case Rep. 2: 148-151. 
Kachuei, R., M. Emami, R. Mirnejad, and M. Khoobdel. 2012. Diversity and frequency of Nocardia spp. in the soil of Isfahan province, Iran. As. Pacif. J. Trop. Biomed. 2: 474-478.

López-Martínez, R. and L. J. Méndez-Tovar. 2007. Chromoblastomycosis. Clin. Dermatol. 25: 188-194.

López-Martínez, R., L. J. Méndez-Tovar, F. Hernández-Hernández y L. R. Castañón-Olivares. 2012. Micosis subcutáneas. pp. 55-75. In: R. López M., L. J. Méndez T., F. Hernández H. y L. R. Castañón O. Micología médica. Procedimientos para el diagnóstico de laboratorio. Trillas. México, D. F. ISBN 978607-17-1092-5.

López-Martínez, R., L. J. Méndez-Tovar, A. Bonifaz, R. Arenas, J. Mayorga, O. Welsh, L. Vera-Cabrera, M. C. PadillaDesgarennes, C. Contreras-Pérez, G. Chávez, R. Estrada, F. Hernández-Hernández, and P. Manzano-Gayosso. 2013. Update on the epidemiology of mycetoma in Mexico. A review of 3933 cases. Gac. Méd. Méx. 149: 586-592.

Lugo-Ayala, S. A., P. Zamudio-Guerra, A. S. López-Cota, F. PicosFernándezy V.F. Muñoz-Estrada. 2002. Estudio de las variantes clínicas, epidemiología y etiología de cromoblastomicosis serie de 108 casos. Trabajos de Investigación. CIMEL 7: 3539.

Macotela-Ruiz, E. y E. Nochebuena-Ramos. 2006. Esporotricosis en algunas comunidades rurales de la Sierra Norte de Puebla. Informe de 55 casos (Septiembre 1995-Diciembre 2005). Gac. Méd. Méx. 142: 377-380.

Madrid, H., J. Cano, J. Gené, and A. Bonifaz, C. Toriello, J. Guarro. 2009. Sporothrix globosa, a pathogenic fungus with widespread geographical distribution. Rev. Iberoam. Micol. 26: 218-222.

Mayorga-Rodríguez, J. A., V. F. Muñoz-Estrada, R. ArosamenaSekisian, R. Morales-Ortiz, D. Fajardo y M. Barba. 1996. Infección nasal y paranasal por Conidiobolus coronatus, primer caso en México. Rev. Iberoam. Micol. 13: 6-7.
Méndez-Tovar, L. J. 2012. Morfología y fisiología de los hongos patógenos. pp. 7-11. In: R. López-Martínez, L. J. Méndez-Tovar y F. Hernández-Hernández (Compiladores). Actualidades en Micología Médica. UNAM. Mexico, D. F.

Munguía-Pérez, R., Y. Romo-Lozano, E. Castañeda-Roldán, M. C. Velázquez-Escobar y A. Espinosa-Texis. 2007. Epidemiología de la esporotricosis en el municipio de Huauchinango, Puebla. Enf. Infec. Microbiol. 27: 38-43.

Padilla-Desgarennes, M. C. 1997. Laboratorio de micología. Rev. Centro Dermatol. Pascua 6: 182-185.

Piontelli, L. E. 2014. Agentes comunes en las aspergilosis humanas: Conceptos primarios en la diferenciación de sus complejos de especies. Bol. Micol. 29: 63-100.

Reza, M. A. and S. G. Amir. 2009. Isolation and characterization of medically important aerobic Actinomycetes of Iran (20062007). Open Microbiol. J. 3: 53-57.

Rippon, J. W. 1988. The subcutaneous mycoses. pp. 276-352. In: J. W. Rippon (ed.). Medical mycology: The pathogenic fungi and the pathogenic actinomycetes. WB Saunders. Philadelphia, PA, USA.

Romero-Navarrete, M., R. Arenas, V. F. Muñoz-Estrada, C. E. Atoche-Diéguez, J. Mayorga-Rodríguez, A. Bonifaz, G. A. Moraila Moya, S. Paredes Solís y A. Castillo Solana. 2014. Cromoblastomicosis en México: Revisión de 603 casos en siete décadas. Dermatología CMQ 12: 87-93.

Vargas-Arzola, J., L. Reyes-Velazco, A. Segura-Salvador y F. Hernández-Hernández. 2012. Cromoblastomicosis por Phialophora verrucosa. Dermatol. Rev. Mex. 78: 141-144.

Vásquez del Mercado, E., R. Arenas y C. Padilla-Desgarennes. 2012. Sporotrichosis. Clin. Dermatol. 30: 437-443. 